\title{
Performance and Thermal Stability of Pt-modified Al-diffusion Coatings for Superalloys under Cyclic and Isothermal Conditions
}

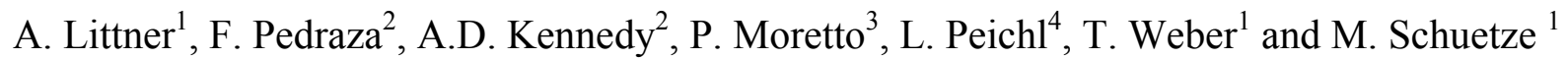 \\ ${ }^{1}$ DECHEMA, e.V., Karl-Winnacker-Institut, Theodor-Heuss-Allee 25, 60489-Frankfurt am \\ Main, GERMANY \\ ${ }^{2}$ SIFCO Turbine Components, Carrigtwohill, Co. Cork, IRELAND \\ ${ }^{3}$ JRC - Institute for Energy. PO Box 2, $1755 Z G$ Petten, The NETHERLANDS \\ ${ }^{4}$ MTU Aero Engines, Turbine Materials, Coatings (TEWT), Dachauer Strasse 665, 80995 \\ München, GERMANY
}

Corresponding author: weber@dechema.de

Keywords: $\quad$ PtAl-diffusion coatings, superalloys, oxidation protection

\begin{abstract}
:
In this paper, the influence of the platinum content on the cyclic oxidation resistance at $1150^{\circ} \mathrm{C}$ of Pt-aluminide coatings deposited on a single crystal Ni-based superalloy is reported. The different coatings involve the well-known bi-phase (Ni,Pt)Al and $\mathrm{PtAl}_{2}$ as well as single phase (Ni,Pt)Al coatings with various compositions and microstructures. The results showed that the cyclic oxidation performance depends strongly on the average Pt-content present in the coating and, to a lesser extent, on the coating microstructure. Moreover, no relevant effect of the Al content could be evidenced. Surface deformation occurred during exposure and was attributed to phase transformations within the coating. This assumption was confirmed by isothermal experiments between 1050 and $1200^{\circ} \mathrm{C}$. Post-experimental investigations of tested specimens were performed by optical and scanning electron microscopy, X-ray diffraction and EPMA.
\end{abstract}




\section{INTRODUCTION}

The beneficial effect of platinum on the capability of NiAl coatings to form a protective alumina scale at high temperature has been reported in many papers [1-9]. According to the literature, the improvement of the oxidation performance of $\beta-\mathrm{NiAl}$ coatings through Ptadditions is mainly achieved due to the enhancement of the alumina scale adherence to the substrate $[3,4]$ and to the ability of the alloy to selectively form a pure $\mathrm{Al}_{2} \mathrm{O}_{3}$ scale even after oxide scale failure during high temperature exposure [5]. The mechanism whereby Pt additions allow such an improvement of oxidation performance is however still not well understood. Many possibilities such as the decrease of growth stresses in the oxide layer, the anchoring of the alumina scale by the formation of oxide pegs, the augmentation of the Al-diffusivity [5-7] have been suggested but have not been unanimously accepted. Moreover there is a lack of data concerning the influence of the Pt-concentration on the oxidation behaviour of the coatings. It has been shown that a minimum Pt-content in the coating should be necessary to ensure the beneficial effects of Pt [10]. Unfortunately, very little data is available in the literature to determine this value which is critical for the development of new coatings with improved oxidation and thermomechanical fatigue life (TMF). Indeed, as it has been shown that mechanical performance is strongly linked to chemical composition [6,9], it appears that the optimisation of the coating chemical composition is not only a key issue in the improvement of the oxidation resistance but also in TMF performance. Thus, efforts to determine the influence of the Pt-content within NiAl coatings were started.

Five Pt-modified coatings with different chemical compositions were tested under isothermal and thermocyclic conditions. The investigations were also focused on the influence of the Alconcentration and of the coating microstructure with regard to the cyclic oxidation resistance.

\section{EXPERIMENTAL}

\subsection{Materials}

The substrate material used to deposit the coatings was the PWA 1484 single-crystal Ni-base superalloy provided by MTU Aero Engines (see the chemical composition in table 1). Button samples (18 mm diameter and $5 \mathrm{~mm}$ thickness) were coated with one two-phase $\beta$ $(\mathrm{Ni}, \mathrm{Pt}) \mathrm{Al} / \mathrm{PtAl}_{2}$ coating and four single-phase $\mathrm{B}-(\mathrm{Ni}, \mathrm{Pt}) \mathrm{Al}$ coatings, produced by MTU Aero Engines and SIFCO Turbine Components. The coatings were deposited using standard industrial routes: platinum electrolytic deposition, aluminising and a subsequent heat treat- 
ment at high temperature. In order to obtain the desired coating composition and microstructure, the thickness of the Pt-layer and the parameters of the aluminising process (pack activity, temperature, time) as well as of the heat treatment had to be adjusted. The influence of the parameters on the composition/structure of the coatings has already been reported elsewhere [11]. A standard Al-diffusion coating without Pt-additions was used as reference.

Tab. 1: Composition of the substrate material (w.-\%)

\begin{tabular}{|l|l|l|l|l|l|l|l|l|l|}
\hline Alloy & Ni & Al & Cr & Co & Ta & W & Mo & Re & Hf \\
\hline PWA 1484 & 59,2 & 5,3 & 5,1 & 9,9 & 7,3 & 6,5 & 1,9 & 4,7 & 0,1 \\
\hline
\end{tabular}

\subsection{Experimental procedure}

\section{Thermocyclic experiments}

Prior to exposure the specimens were degreased through an ultrasonic bath using methanol for a period of 15 minutes. After being dried in hot air, the specimens were immediately introduced in the experimental rig. The samples were placed on a fixed mullite sample-holder. A tubular furnace guided on tracks is moved over the sample holder during the heating period. For cooling the furnace is moved away within $2 \mathrm{~min}$. A thermocouple of type $\mathrm{S}$ was used to periodically calibrate the working zone temperature of the furnace during the tests. The accuracy of the temperature was maintained within $1150 \pm 8{ }^{\circ} \mathrm{C}$. In order to ensure the measurement of the total mass change of the samples including spalled flakes, each sample was introduced into an individual $\mathrm{Al}_{2} \mathrm{O}_{3}$ crucible. The mass change of the crucible containing the specimen was recorded separately from that of the specimen. All measurements were repeated three times.

Cyclic oxidation tests were performed at $1150{ }^{\circ} \mathrm{C}$ in laboratory air. Each cycle consisted of $1 \mathrm{~h}$ at $1150{ }^{\circ} \mathrm{C}, 44 \mathrm{~min}$ at ambient temperature and $16 \mathrm{~min}$ reheating (Fig. 1). The sample temperature reached during cooling was about $70{ }^{\circ} \mathrm{C}$. The temperature profile was measured by a thermocouple in close contact with the tested specimens.

Isothermal experiments were performed in a muffle furnace. The specimens were inserted into the hot furnace and were subjected to air cooling after exposure. The experiments were done at temperatures of $1050,1100,1150$ and $1200{ }^{\circ} \mathrm{C}$ for $1500 \mathrm{~h}$ interrupted after 50,250 and $750 \mathrm{~h}$ for examination of the specimens. 


\subsection{Microscopy, microanalysis and X-ray diffraction}

After completion of the tests, the specimens were Ni-plated, embedded, ground and polished to a $1 \mu \mathrm{m}$ finish for optical microscopy, SEM (Philips equipped with an EDS analysis system) and EPMA (Cameca SX-50) investigations. For etching a solution consisting of $\mathrm{H}_{2} \mathrm{O}+40 \mathrm{ml}$ $\mathrm{HCl}+100 \mathrm{ml} \mathrm{HNO}$ was used.

\section{RESULTS AND DISCUSSION}

\subsection{Specimens in the as-received conditions}

\subsubsection{Microstructure}

\section{Coating 1}

Coating 1 was a $63 \mu \mathrm{m}$ thick coating exhibiting 3 different zones (Fig. 2). The outermost layer consisted of a mixture of $\mathrm{B}-(\mathrm{Ni}, \mathrm{Pt}) \mathrm{Al}$ and $\zeta-\mathrm{PtAl}_{2}$ grains with some alloying element particles (Mo, W, Re and Ta) in the lowest part of the zone.

The intermediate zone was composed of the $\mathrm{B}-(\mathrm{Ni}, \mathrm{Pt}) \mathrm{Al}$ phase exhibiting significant a amount of precipitates. The interdiffusion zone (IZ) consisted of $\beta-(\mathrm{Ni}, \mathrm{Pt}) \mathrm{Al}$ containing a fine mixture of alloying element precipitations. The size of the $\beta$-phase grains was close to 7-8 $\mu \mathrm{m}$. The $\zeta$ $\mathrm{PtAl}_{2}$-phase was mainly located at the boundaries of the $\beta$-phase grains, to a minor extent small $\zeta$-precipitates were observed also within the $\beta-N i A l$ grains. As shown in the right part of Fig. 2, the surface of the coating was smooth, also exhibiting the arrangement of $\zeta-\mathrm{PtAl}_{2}$ around the $\beta$-phase grains.

\section{Coatings 2,3 and 4}

All three coatings consisted of a $\beta-(\mathrm{Ni}, \mathrm{Pt}) \mathrm{Al}$ single phase main coating followed by an interdiffusion zone composed of a fine mixture of alloying element precipitates. The average thicknesses of coatings 2, 3 and 4 including the interdiffusion zones were 80, 62 and $76 \mu \mathrm{m}$, respectively. Significant differences in size and distribution of the grains could be observed. Indeed, main coating 2 (Fig. 3 left) was composed of a single row of grains $\left(\mathrm{GS}_{\mathrm{x}} \sim 40 \mu \mathrm{m}\right.$ and $\mathrm{GS}_{\mathrm{y}} \sim 200-300 \mu \mathrm{m}$ ) while main coating 3 was exhibiting two different zones (Fig. 3 right): an upper grain layer consisting of fine grains $\left(\mathrm{GS}_{\mathrm{x}}<5 \mu \mathrm{m}\right.$ and $\left.\mathrm{GS}_{\mathrm{y}} \sim 5 \mu \mathrm{m}\right)$ and a lower layer in contact with the interdiffusion zone composed of larger grains $\left(\mathrm{GS}_{\mathrm{x}} \sim 6 \mu \mathrm{m}\right.$ and $\mathrm{GS}_{\mathrm{y}} \sim 10$ $\mu \mathrm{m})$. 
Main coating 4 (Fig. 4) also showed 2 different zones: here the upper zone exhibited large grains $\left(\mathrm{GS}_{\mathrm{x}} \sim 50 \mu \mathrm{m}\right.$ and $\left.\mathrm{GS}_{\mathrm{y}} \sim 23 \mu \mathrm{m}\right)$ whereas the lower zone was composed of fine grains $\left(\mathrm{GS}_{\mathrm{x}} \sim 15 \mu \mathrm{m}\right.$ and $\left.\mathrm{GS}_{\mathrm{y}} \sim 28 \mu \mathrm{m}\right)$.

It could be observed that the coatings exhibiting large Pt-modified B-NiAl grains close to the coating surface (coatings 2 and 4) had smooth surfaces composed of grains outlined by grainboundary ridges. As indicated in the literature [4], such morphology should be typical of an outwardly growing coating. On the contrary, the fine-grained coating 3 had a rough surface composed of small B-(Ni,Pt)Al grains more or less detached from the surface (Fig. 5).

\section{Coating 5}

Coating 5 had a microstructure composed of fine grains $(<5 \mu \mathrm{m})$ quite similar to those of coating 3. However, a significant density of alloying element precipitates particularly rich in $\mathrm{W}, \mathrm{Ta}$ and $\mathrm{Cr}$ was present in the main coating. The coating surface was rough and porous. It was also possible to observe the presence of the fine alloying element precipitates on the surface.

\subsubsection{Chemical composition}

The concentration profiles shown in Fig. 6 indicate quite low Al-gradients within the outer $30 \mu \mathrm{m}$ of the five coatings. The Al-contents were different according to the nature of the respective coating.

Coating 1, due to the presence of the $\mathrm{PtAl}_{2}$ phase, revealed the highest $\mathrm{Al}$-content up to $\sim 56$ at.-\% close to the coating surface. The concentration curve showed however a rapid decrease of the Al-content down to $\sim 12$ at.- $\%$ at a distance of $60 \mu \mathrm{m}$ from the surface. Coatings 2 and 3 revealed Al-plateaus at $\sim 39$ and $\sim 38$ at.-\%, respectively. Coating 4 exhibited a decrease of the Al-concentration from $\sim 48$ to $\sim 16$ at.\% within $80 \mu \mathrm{m}$. The Al-profile of coating 5 showed concentrations close to 47 at.- $\%$ at the surface. The discontinuities observed in the middle parts of the profiles are due to the presence of alloying element precipitates in these regions. The Pt-concentration curves typically showed two different kinds of behaviour. Coatings 1 and 5 exhibited significant Pt-gradients characterised by high concentrations close to the coating surface $(\sim 9.5$ and $\sim 8.1$ at.- $\%$, respectively) decreasing quickly to zero in the vicinity of the interdiffusion zone. On the contrary, the Pt-concentration profiles of coatings 2 , 3 and 4 showed plateaus throughout the main coating at $\sim 4.7, \sim 3.9$ and $\sim 2.6$ at.- $\%$, 
respectively. Subsequently, the Pt-content showed a slight decrease within the interdiffusion zone before suddenly dropping down to the zero value at the coating/substrate interface.

A very good symmetry between increase/decrease of the Pt-content and decrease/increase of the $\mathrm{Ni}$-content in the main coatings was found, indicating, that $\mathrm{Pt}$ substitutes $\mathrm{Ni}$ in the $\mathrm{B}-\mathrm{NiAl}$ structure. With regards to the chemical composition, the remaining alloying elements could be separated in two groups: (Co, Cr) and the refractory elements (Ta, Mo, W and $\mathrm{Re}$ ). From EPMA profiles, it appeared that $\mathrm{Co}$ and $\mathrm{Cr}$ were incorporated into the $\mathrm{B}-(\mathrm{Ni}, \mathrm{Pt}) \mathrm{Al}$ phase. The contents within the main coatings typically varied between $\sim 3.0$ and $\sim 7.0$ at.- $\%$ for Co and between $\sim 1.0$ and $\sim 3.0$ at.-\% for Cr. Apart from Ta (contents up to $\sim 0.9$ at.- $\%$ could be found in the $\beta$-phase), the solubility of the refractory elements in the $B-(\mathrm{Ni}, \mathrm{Pt}) \mathrm{Al}$ phase could be assumed to be negligible. However, some RE could be detected within precipitates. As expected, the concentration of the heavy alloying elements significantly increased in the interdiffusion zone.

\subsection{Cyclic oxidation tests}

The results of the weight change measurements are shown as a function of the number of cycles in Fig. 7. Based on the curves, the coatings could be merged into two groups:

- Coatings 1,2 and 3 have a good resistance to cyclic oxidation exhibiting positive weight gains up to 1665,1701 and 1288 cycles, respectively.

- Coatings 4 and 5 have a low resistance to cyclic oxidation exhibiting positive weight gains up to 350 and 289 cycles, respectively.

- For the Al-reference coating weight loss starts after 75 cycles

The optical inspection of the specimens after the first cycles revealed for each coating the formation of a brownish oxide layer identified by XRD as $\alpha-\mathrm{Al}_{2} \mathrm{O}_{3}$. The detail of the curves close to the zero weight change line indicated different mass gain kinetics as function of the coating quality. Indeed, one could observe that in spite of the formation on each coating of a macroscopically identical $\alpha-\mathrm{Al}_{2} \mathrm{O}_{3}$ scale, coating 5 exhibited during the first 50 cycles much higher mass gain kinetics in comparison with coatings 1, 2, 3 and 4 showing similar weight changes. 
SEM investigations of the coating surfaces confirmed that the oxide scales formed on coatings 1, 2, 3 and 4 were exclusively composed of alumina. However, different kinds of oxide scale structures could be evidenced. In fact, coating 1 (Fig. 8 a) revealed a scale consisting of $\mathrm{Al}_{2} \mathrm{O}_{3}$ platelets growing at the grain boundaries of the $\beta-(\mathrm{Ni}, \mathrm{Pt}) \mathrm{Al}$ grains. On the contrary, coatings 2, 3 and 4 developed typical ridged structures as a result of Al-outward diffusion [12]. As shown in Fig. 8 c, intrinsic ridges growing at the grain boundaries of the $\beta$-grains as well as fine extrinsic ridges growing within the grains along cracks very likely formed through volume contraction induced by the $\theta-\mathrm{Al}_{2} \mathrm{O}_{3}$ to $\alpha-\mathrm{Al}_{2} \mathrm{O}_{3}$ transformation [12-14]. Thus, the presence of extrinsic ridges indicated that the formation of the transient $\theta-\mathrm{Al}_{2} \mathrm{O}_{3}$ structure initially occurred at $1150^{\circ} \mathrm{C}$ on the surface of coating 3 . Contrary to this coating, only a single type of ridges could be evidenced on the surface of coatings 2 and 4 . No cracks arising from the possible $\theta$ to $\alpha$ transformation could be detected. It is to emphasize that, as the nature of the alumina formed during the early oxidation stages depends strongly on the morphology and finishing of the surface [15], the formation of $\theta-\mathrm{Al}_{2} \mathrm{O}_{3}$ is not necessarily awaited.

The surface of coating 5 (Fig. 9) revealed the formation of a porous $\alpha-\mathrm{Al}_{2} \mathrm{O}_{3}$ scale containing fine oxide precipitates rich in $\mathrm{Ni}, \mathrm{Cr}$ and $\mathrm{Co}$ that could not be detected through $\mathrm{XRD}$ measurements. The presence of such foreign oxides could explain the high mass gains during the early oxidation stages.

Prolonged exposures allowed to macroscopically differentiate the behaviour of the coatings through the appearance of blue oxide particles that could be identified due to XRDmeasurements as $\mathrm{NiAl}_{2} \mathrm{O}_{4}$ spinel particles [16]. Coatings 1 and 2 did not show any spinel particles until $\approx 1250$ and $\approx 1000$ cycles, respectively. On the contrary, coatings 3,4 and 5 started to reveal significant formation of spinels after $\approx 300, \approx 120$ and $\approx 80$ cycles, respectively. It was obvious that the beginning of spinel formation coincided with the onset of spallation of the oxide scale. As spallation continued also the formation of Ta-rich oxides and finally $\mathrm{NiO}$ did occur.

SEM investigations of the surface at different intervals during cyclic exposure revealed significant rumpling as shown for coating 1 in Fig. 10. The deformation typically occurred as follows: 1) appearance of the first rumples after 100-200 cycles, 2) growth of the rumple amplitude, 3) opening of cracks on the top of the rumples, 4) spallation of the oxide scale, Al- 
depletion, formation of mixed oxides and finally 5) rapid degradation of the coating by massive spallation and formation of $\mathrm{NiO}$.

It was found that the occurrence of rumpling is connected with phase transformations within the coating. This mechanism was proposed by Tolpygo [15]. The continued depletion of Al leads to a $\beta-\gamma^{\prime}$ and finally to a $\gamma^{\prime}-\gamma$ transformation as shown in Fig. 11.

The micrographs show that rumple formation starts along with the appearance of the $\gamma^{\prime}-$ $\mathrm{Ni}_{3} \mathrm{Al}$-phase, probably due to Al-depletion following alumina formation on the coating surface. The surface deformation proceeds with growing rumple amplitude as $\beta-\gamma^{\prime}$ transformation occurs also in the inner regions of the coating. Calculations of the volume change during phase transformation revealed that during $\beta-\gamma^{\prime}$ transformation a higher volume contraction has to be expected than during $\gamma^{\prime}-\gamma$ transformation. Consequently the surface rumpling tends to disappear when the $\beta-\gamma^{\prime}$ transformation is completed as shown in the lower micrographs of Fig. 11.

In order to establish a better understanding of the parameters influencing the cyclic oxidation resistance, the effect of the coating composition has been considered. The Pt- and Alconcentrations were correlated with the coating lifetime as shown in Fig. 12. It may be concluded, that the Al-content is not relevant for the coating lifetime in this Al-concentration range since coating 4 with a low Al-content could outperform coating 5 with a significantly higher Al-content while both coatings having a similar Pt-content. However, to obtain extended coating lifetimes a minimum Pt-content of about 3 at.-\% seems to be necessary if the performance of coatings 1,2 and 3 is analysed

\subsection{Isothermal oxidation tests}

Isothermal exposure was done with the PtAl-coatings 1 and 2 at temperatures of 1050, 1100, 1150 and $1200{ }^{\circ} \mathrm{C}$ up to $1500 \mathrm{~h}$ interrupted after 50,250 and $750 \mathrm{~h}$ for examination of the specimens. Compared to the thermocyclic experiments overall quite similar coating lifetimes and surface degradation modes were found. The specific morphology of the coatings leads to different oxidation behaviour at 1050 and $1100{ }^{\circ} \mathrm{C}$. Micrographs for the two-phase coating (coating 1) and the single-phased coating 2 are depicted in Fig. 12. The two-phase morphology of coating 1 has disappeared after $50 \mathrm{~h}$. Alloying elements were found to diffuse outward after $250 \mathrm{~h}$ and the onset of $\beta-\gamma^{\prime}$ transformation was present after $1500 \mathrm{~h}$. On the 
contrary the single phased coating 2 showed after $1500 \mathrm{~h}$ no changes of the morphology. The same findings were made for the experiments at $1100{ }^{\circ} \mathrm{C}$.

At 1150 and $1200{ }^{\circ} \mathrm{C}$, however, the behaviour of both coatings tends to become similar. Phase transformations were present also within coating 2 as shown in Fig. 13. At the same time extensive surface rumpling could be observed. The different behaviour between both coatings may be attributed to the variation of the microstructure. The very fine-grained morphology of coating 1 (see fig. 2) allows quite rapid interdiffusion leading to the dissolution of the $\zeta$ $\mathrm{PtAl}_{2}$-phase and the outward diffusion of alloying elements and eventually to the onset of the $\beta-\gamma^{\prime}$ transformation due to Al-depletion. On the contrary the very large grains of coating 2 (see fig. 3) facilitate prolonged stability of the $\beta$-phase due to a considerable reduction of diffusion paths. The behaviour of both coatings becomes similar with increasing temperatures where bulk diffusion is more pronounced.

\section{CONCLUSION}

Thermocyclic and isothermal exposure was performed for Pt-modified Al-diffusion coatings on a Ni-base superalloy. The investigations led to the conclusion that a significant improvement of coating lifetime compared to simple Al-diffusion coatings can be possible if the average Pt-content within the coating exceeds a minimum value of about 3 at.- $\%$.

The main degradation mechanism for Pt-Al-coatings with Pt-contents in excess of 3 at.- $\%$ was identified as inward diffusion of Al leading eventually to $\beta-\gamma^{\prime}-\gamma$ phase transformation. Obviously Pt can not act as diffusion barrier. As Al-depletion proceeds the formation of fast growing oxides of alloying elements within the originally pure $\alpha$-alumina oxide layer leads to break-away oxidation and extensive spallation.

On the contrary on simple Al-diffusion coatings and coatings with minor Pt-additions spallation is observed very early resulting in lower lifetimes.

The rumpling phenomenon occurring during thermocyclic experiments seemed to be connected with the phase transformations within the coatings. By additional isothermal experiments it could be confirmed, that not necessarily cyclic oxidation conditions have to be present for the occurrence of rumpling. The experiments revealed that phase transformations and the accompanying volume contractions are responsible for considerable surface deformation. 


\section{AKNOWLEDGEMENTS}

The authors would like to thank Mrs. D. Hasenpflug, Mrs. E. Berghof-Hasselbaecher for the specimen preparation and optical microscopy, Mrs. Schorr for EPMA, Mr. Gawenda for SEM investigations and Mr. Jusek for XRD-measurements. The financial support of the project ORDICO by the EU under contract no. G4RD-CT-2000-00319 is gratefully acknowledged.

\section{LITERATURE}

[1] A.L. Purvis, B.M. Warnes

The effects of platinum concentration on the oxidation resistance of superalloys coated with single-phase platinum aluminide, Surface and Coatings Technology (2001) no. $146-147,1-6$

[2] J. Angenete, K. Stiller

A comparative study of two inward grown Pt modified Al diffusion coatings on a single crystal Ni base superalloy, Materials Science and Engineering A (2001) no. 316, 182-194

[3] E.J. Felten, F.S. Pettit

Development, growth and adhesion of $\mathrm{Al}_{2} \mathrm{O}_{3}$ on platinum-aluminum alloys Oxidation of Metals 10 (1976) 189-223

[4] Y. Zhang, W.Y. Lee, J.A. Haynes, I.G. Wright, B.A. Pint, K.M. Cooley, P.K. Liaw Synthesis and cyclic oxidation behavior of a $(\mathrm{Ni}, \mathrm{Pt}) \mathrm{Al}$ coating on a desulfurized $\mathrm{Ni}$ base superalloy, Metallurgical Transactions A 30A (1999) 2679-2687

[5] E.J. Felten Use of platinum and rhodium to improve oxide adherence on $\mathrm{Ni}-8 \mathrm{Cr}-6 \mathrm{Al}$ alloys Oxidation of Metals 10 (1976) 23-28

[6] J.G. Fountain, F.A. Golightly, F.H. Stott, C.G. Wood The Influence of Platinum on the Maintainance of $\mathrm{a}-\mathrm{Al}_{2} \mathrm{O}_{3}$ as a Protective Scale, Oxidation of Metals 5 (1976) 341-345

[7] B. Gleeson, W. Wang, S. Hayashi, D. Sordelet Effetcs of Platinum on the Interdiffusion and Oxidation Behavior of Ni-Al based 
Alloys, 6th International Symposium on High Temperature Corrosion and Protection of Materials, Les Embiez, France, 16-21 May 2004 (2004)

[8] N.M. Yanar, G.H. Meier, F.S. Pettit

The influence of platinum on the failure of EBPVD YSZTBCs on NiCoCrAlY bond coats, Scripta Materialia 46 (2002) 325-330

[9] J.H. Chen, J.A. Little

Degradation of the platinum aluminide coating on $\mathrm{CMSX} 4$ at $1100^{\circ} \mathrm{C}$

Surface and Coatings Technology 92 (1997) 69-77

[10] G.R. Krishna, D.K. Das, V. Singh, S.V. Joshi,

Role of Pt content in the microstructural development and oxidation performance of Pt-aluminide coatings produced using a high activity aluminizing process, Materials Science and Engineering A, vol. 251, 1998, 40-47

[11] F. Pedraza, P. Moretto, Investigation of the microstructure of platinum-modified aluminide coatings, to be published

[12] V. K. Tolpygo , D. R. Clarke

Microstructural evidence for counter-diffusion of aluminium and oxygen during the growth of alumina scales, Materials at High Temperatures 20 (2003) no. 3, 261-271

[13] H.M. Hindam, W.W. Smeltzer

Growth and microstructure of alpha-A12O3 on ss-NiA1, J. Electrochem. Soc. 127 (1980) no. 7, 1630-1635

[14] B.A. Pint, M. Treska, L.W. Hobbs The effect of various oxide dispersions on the phase composition and morphology of $\mathrm{Al}_{2} \mathrm{O}_{3}$ scales grown on beta-NiAl, Oxidation of Metals 47 (1997) 1-20

[15] V. K. Tolpygo, D. R. Clarke Surface Rumpling of a (Ni, Pt)Al Bond Coat Induced by Cyclic Oxidation, Acta materialica 48 (2000) no. 13, 3283 - 3293

[16] A. Littner, M. Schuetze The Cyclic Oxidation Behaviour of Several Aluminide and Platinum Aluminide Diffusion Coatings at $1150^{\circ} \mathrm{C}$, International Conference Corrosion Science in the $21 \mathrm{st}$ Century, UMIST, Manchester, July 2003 

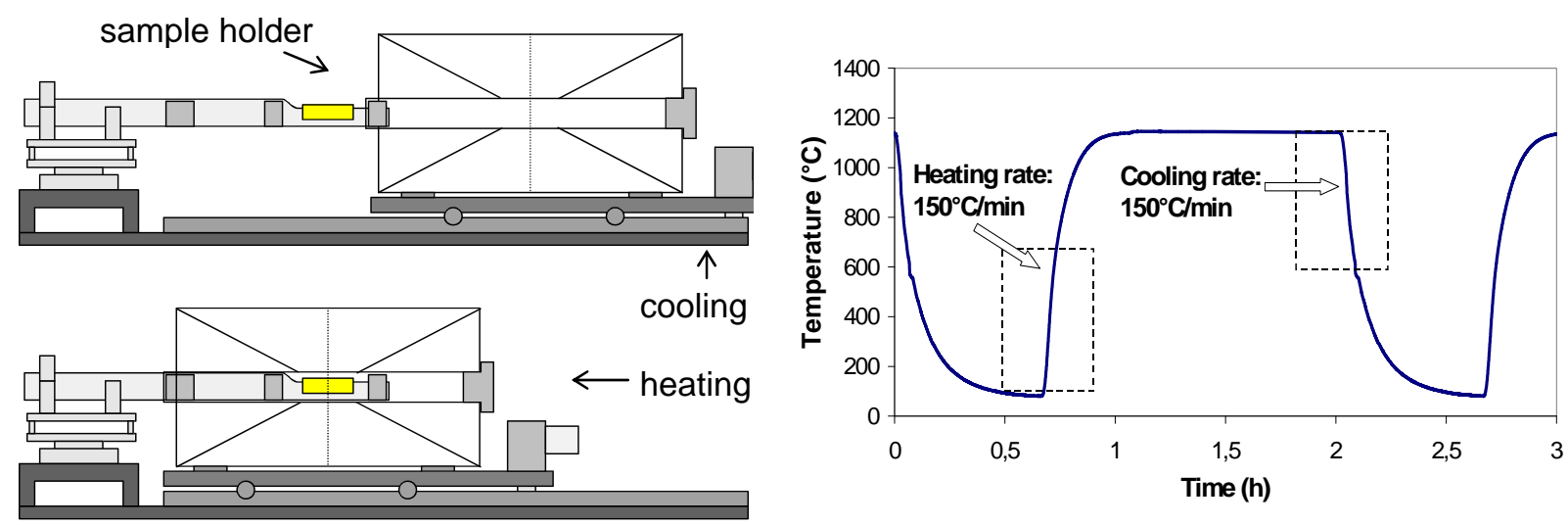

Fig. 1: Experimental setup for thermocyclic experiments (left), temperature cycle (right)
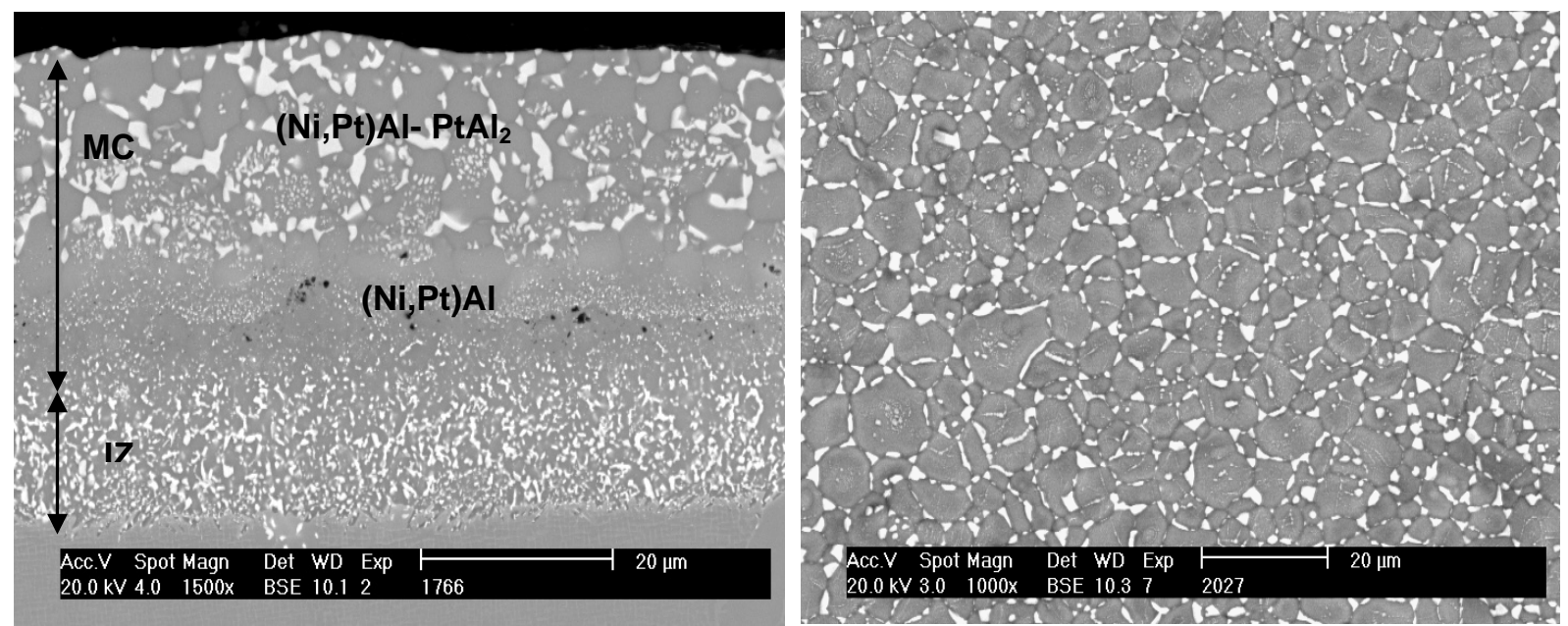

Fig. 2: Cross section (left) and top view (right) of the dual phase Pt-modified NiAl-coating $(\mathrm{MC}=$ main coating, $\mathrm{IZ}=$ interdiffusion zone $)$
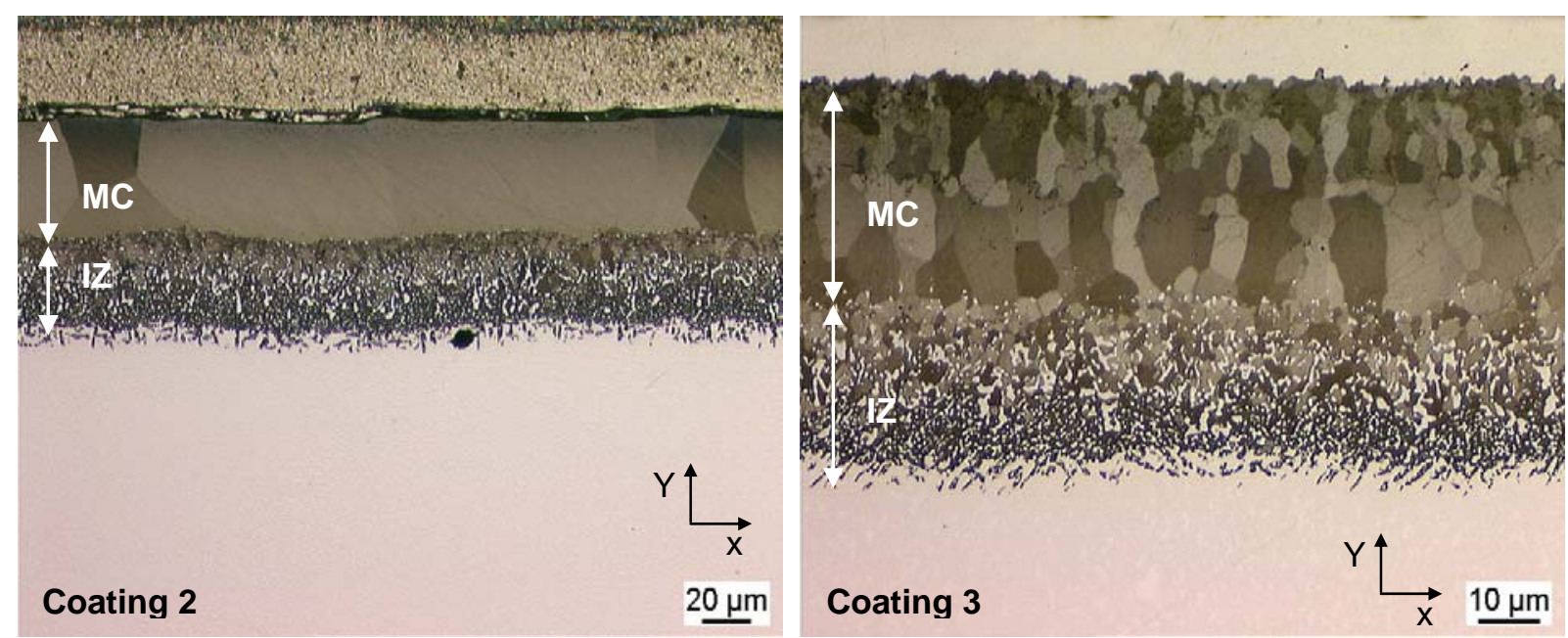

Fig. 3: Cross sections of the single phased Pt-modified NiAl-coating 


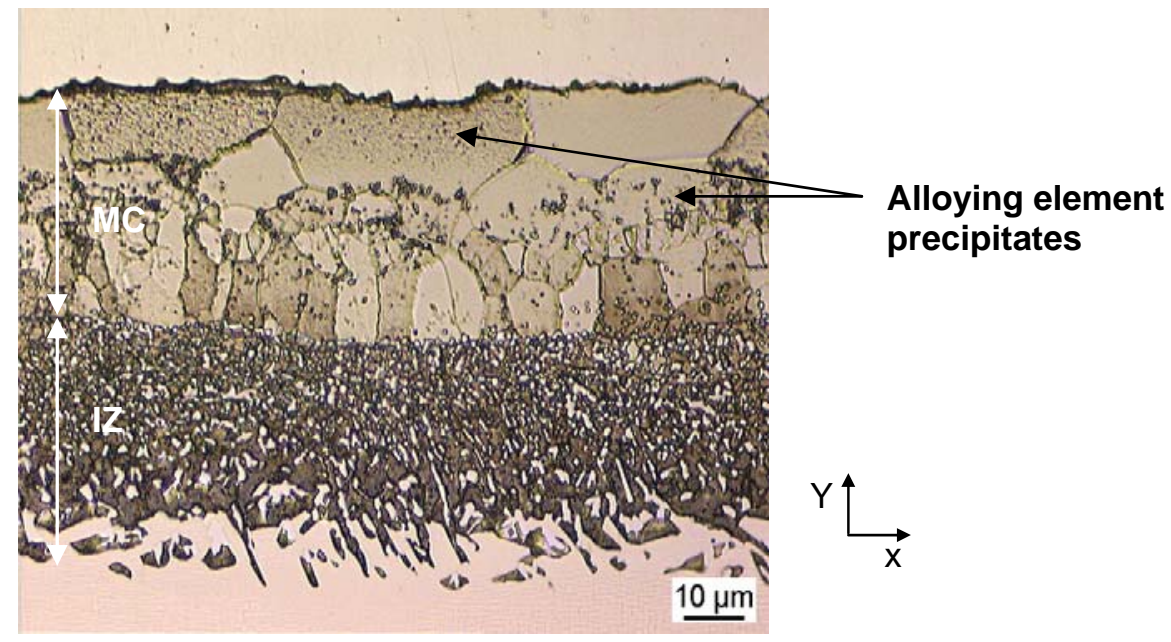

Fig. 4: Cross section of coating 4
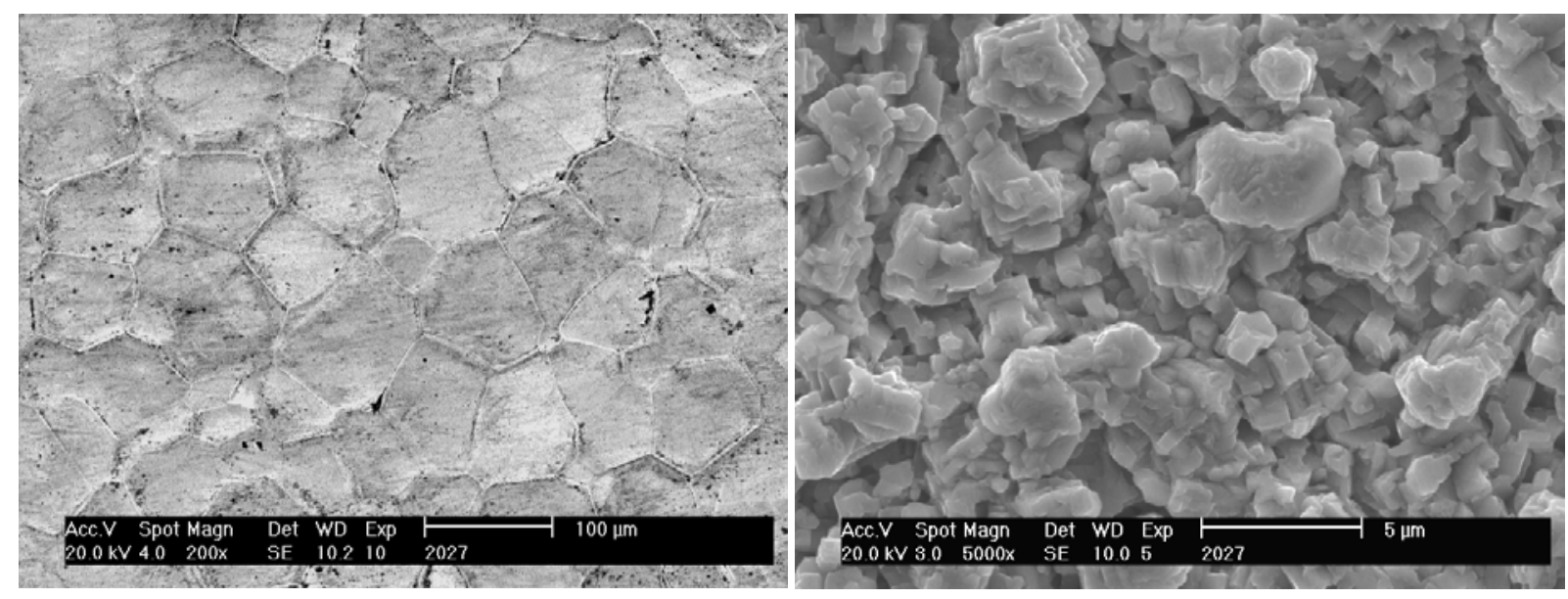

Fig. 5: Surface of coating 2 (left) and coating 3 (right) 

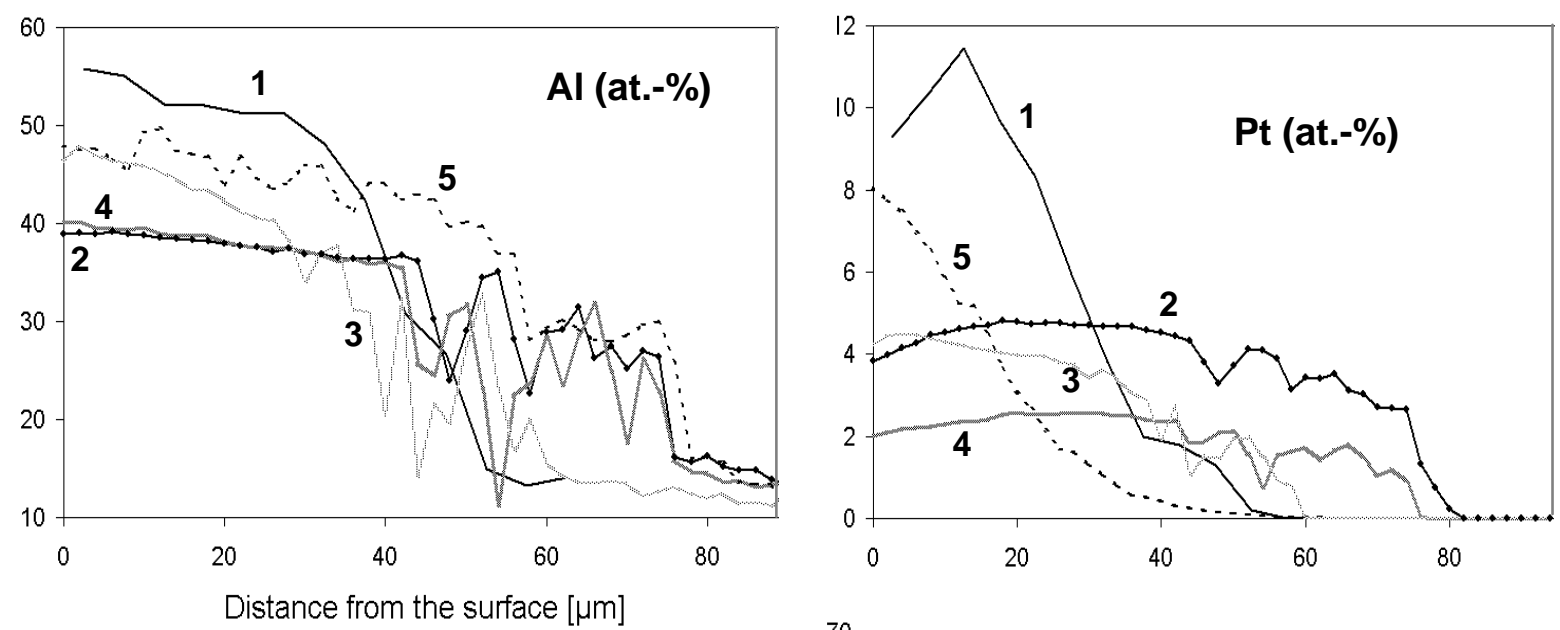

Fig. 6:

$\mathrm{Al}-, \mathrm{Pt}$ and $\mathrm{Ni}-$

concentration profiles of the coatings obtained by

EPMA-linescan
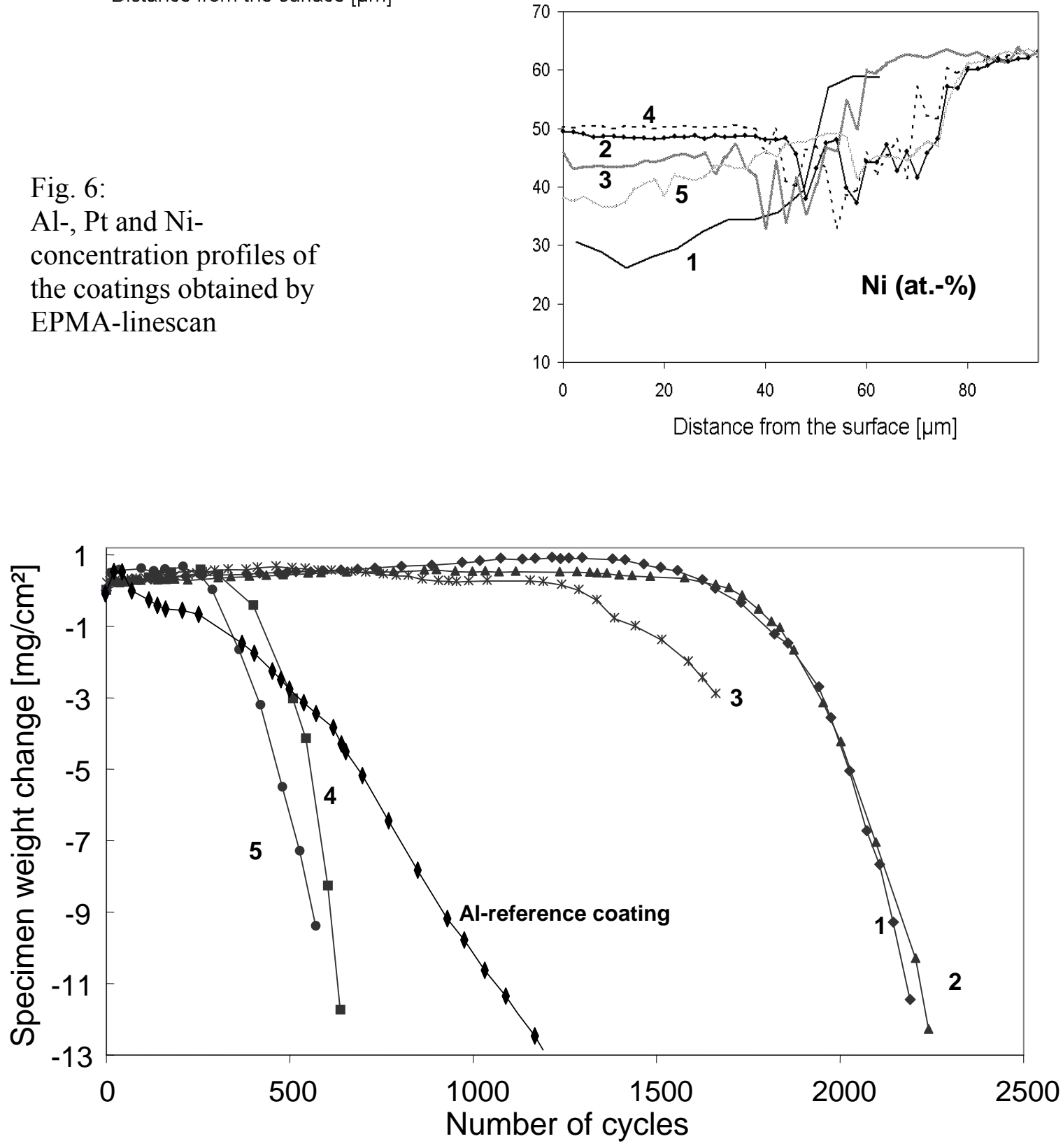

Fig. 7: Weight change curves during cyclic oxidation testing $\left(\mathrm{T}_{\max }=1150^{\circ} \mathrm{C}\right)$ 


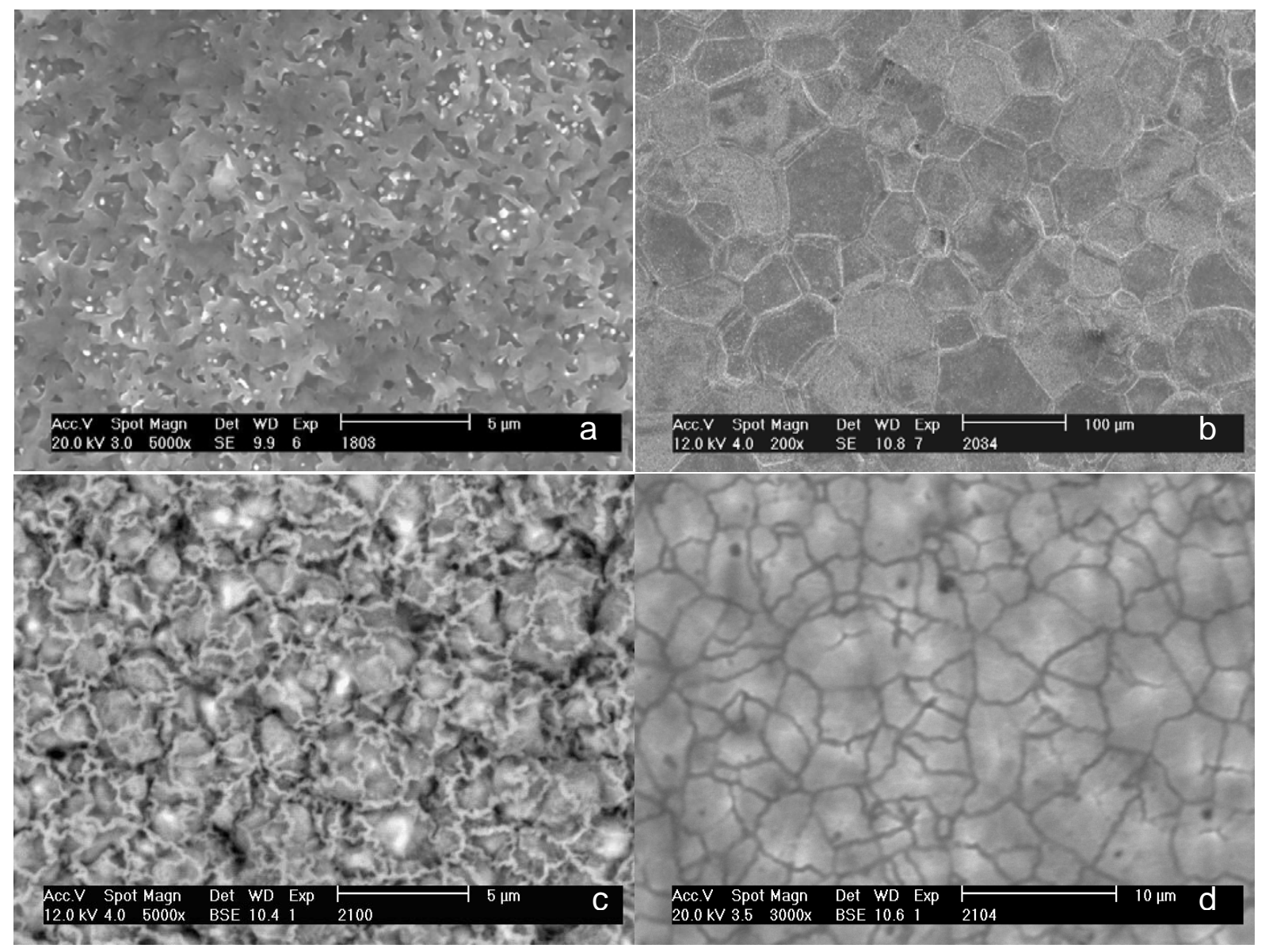

Fig. 8: Surface morphology of coating 1-4 (a-d) after 50 cycles 


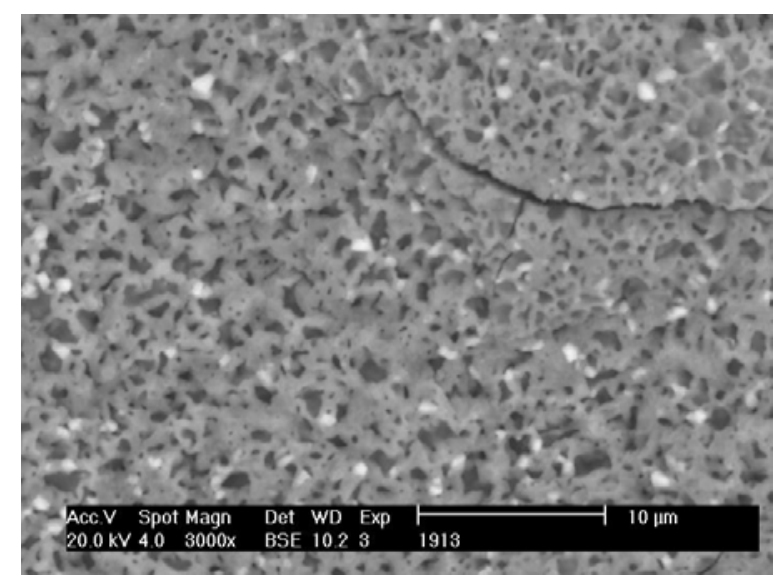

Fig. 9:

Surface morphology of coating 5 after 50 cycles
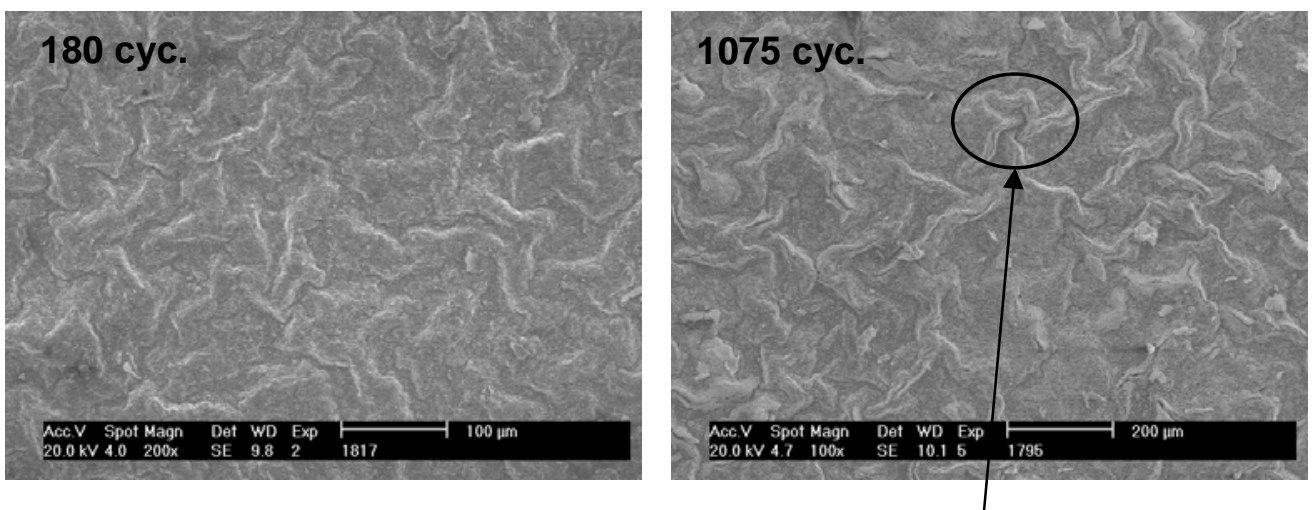

Fig. 10:

Development of surface rumpling on coating 1 during cyclic oxidation
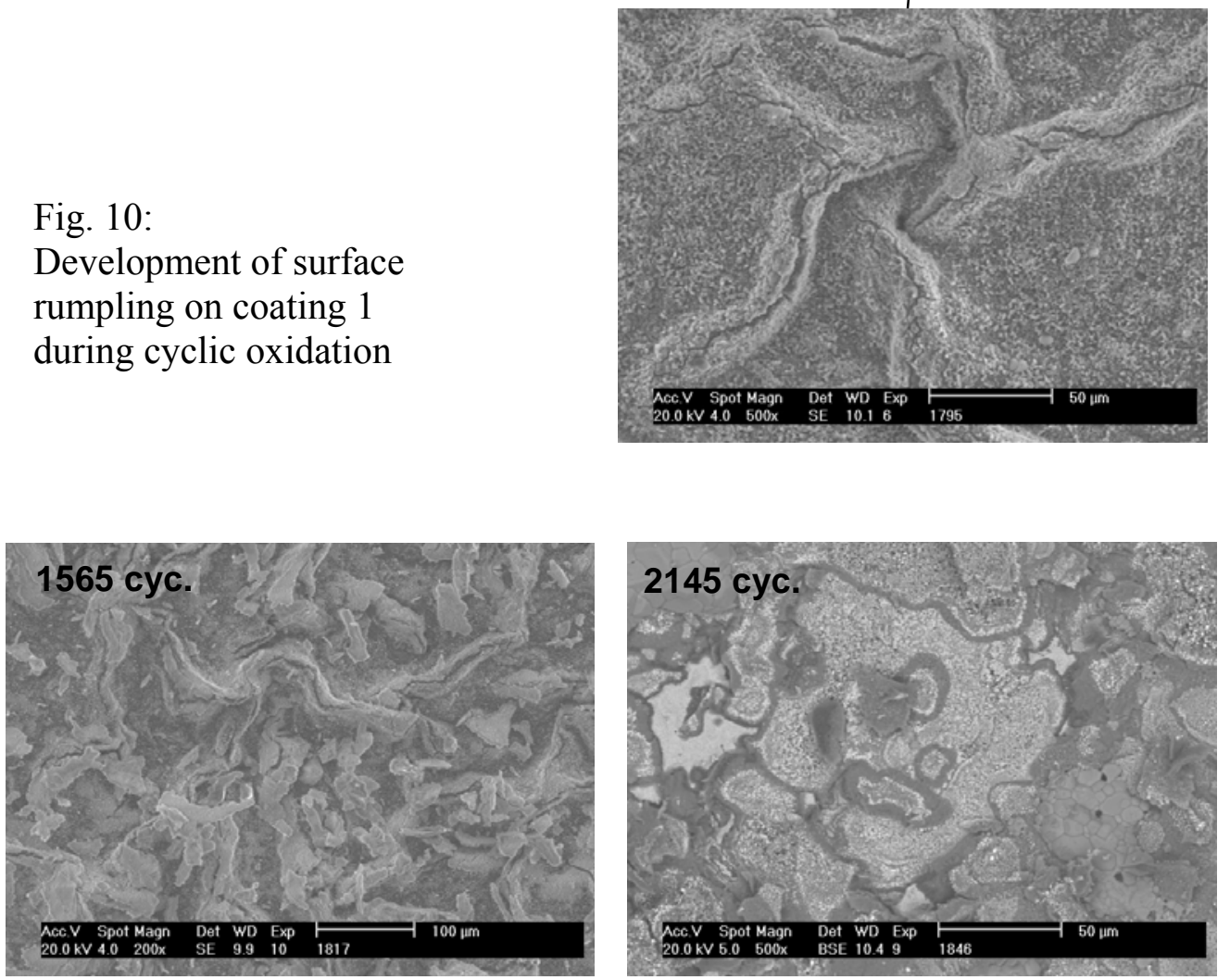

Fig. 10. (cont.): Extensive spallation and mixed oxide formation on coating 1 

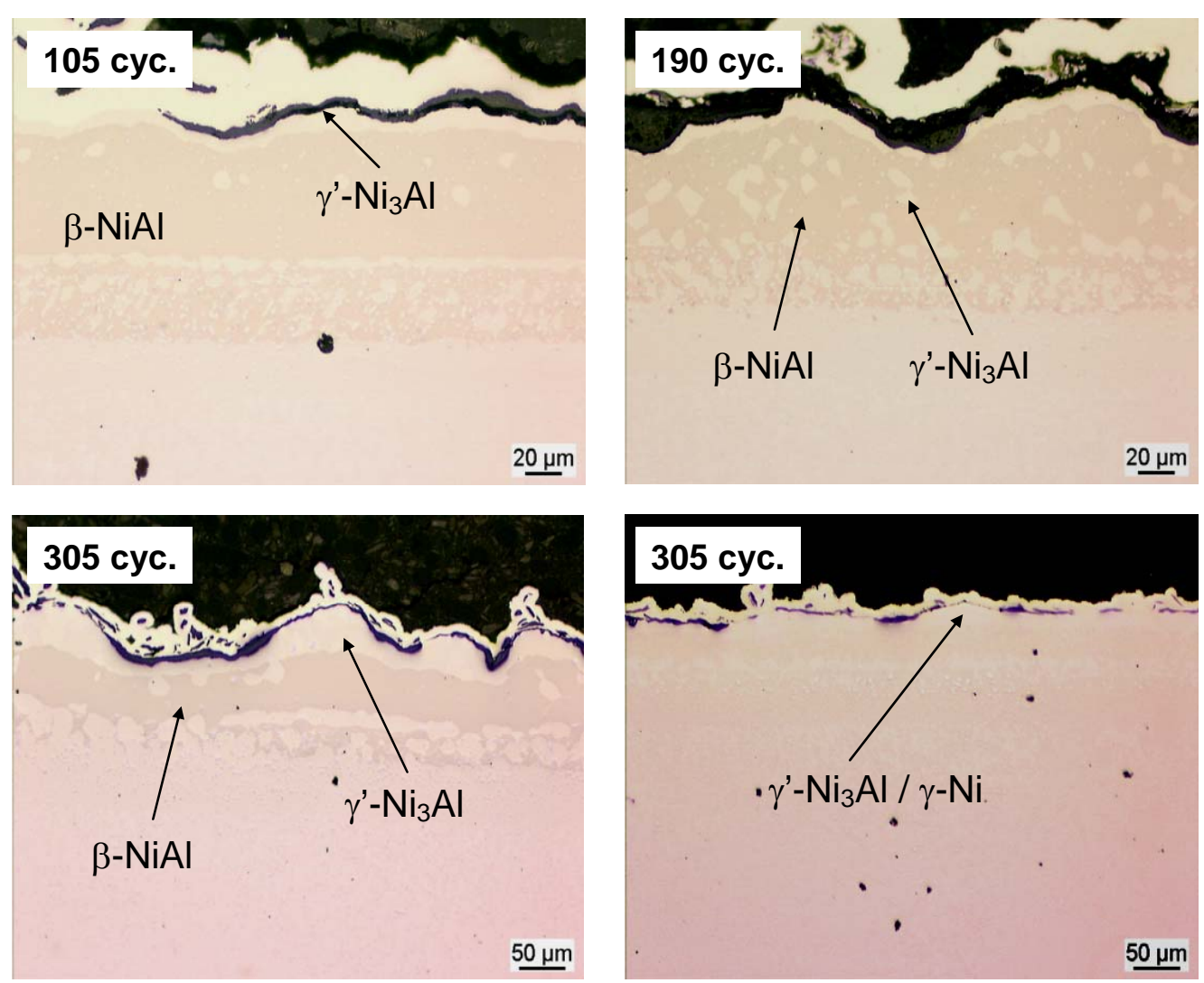

Fig. 11: Examples of phase transformations in the $\mathrm{Al}$ reference coating, note: the lower micrographs are taken from the same specimen at different locations

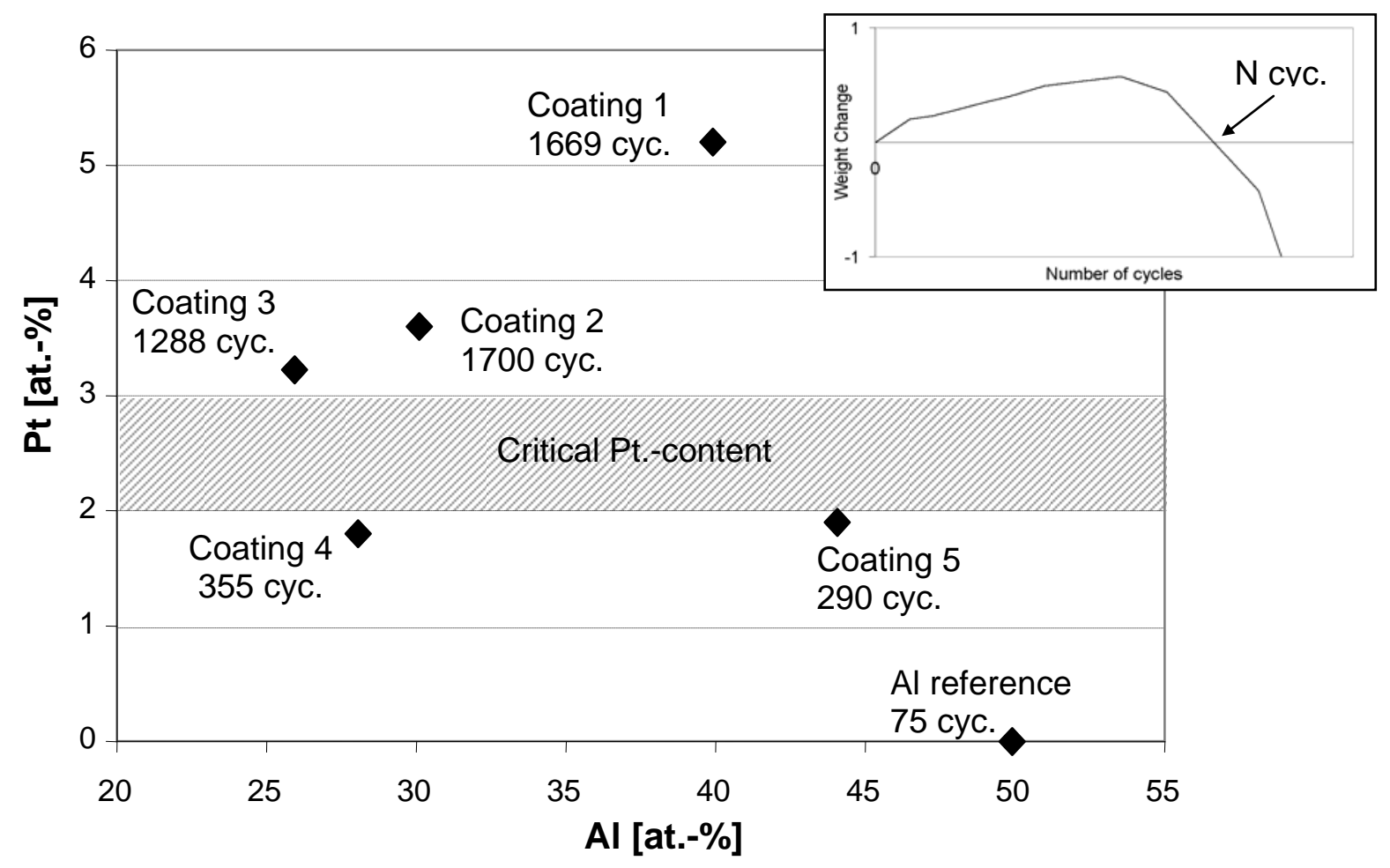

Fig. 12: Al/Pt-ratio averaged over coating thickness and coating lifetime 

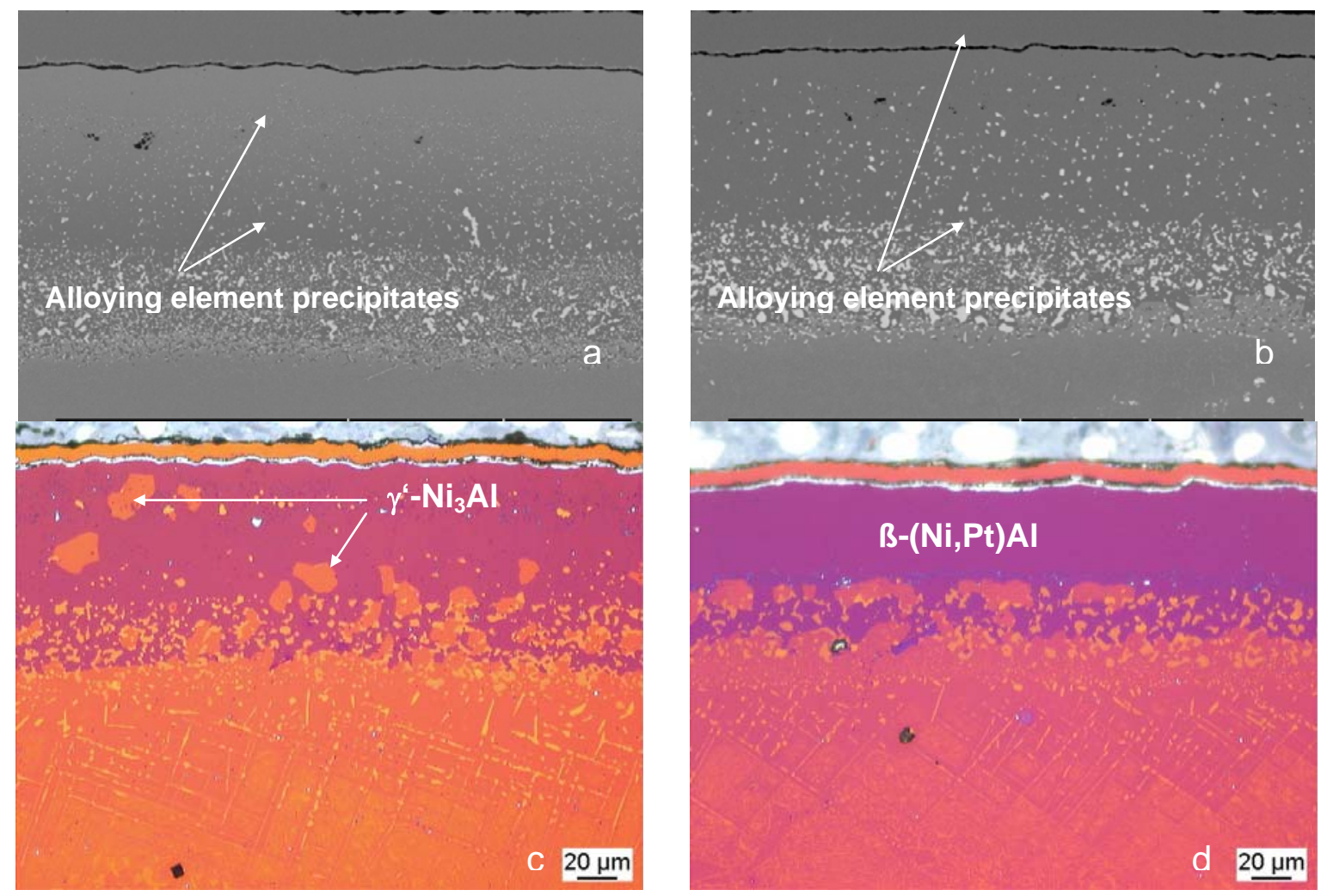

Fig. 12: Isothermal exposure at $1050{ }^{\circ} \mathrm{C}$, coating 1 after a) $\left.\left.50 \mathrm{~h}, \mathrm{~b}\right) 250 \mathrm{~h}, \mathrm{c}\right) 1500 \mathrm{~h}$ and coating 2 after $1500 \mathrm{~h}(\mathrm{~d})$

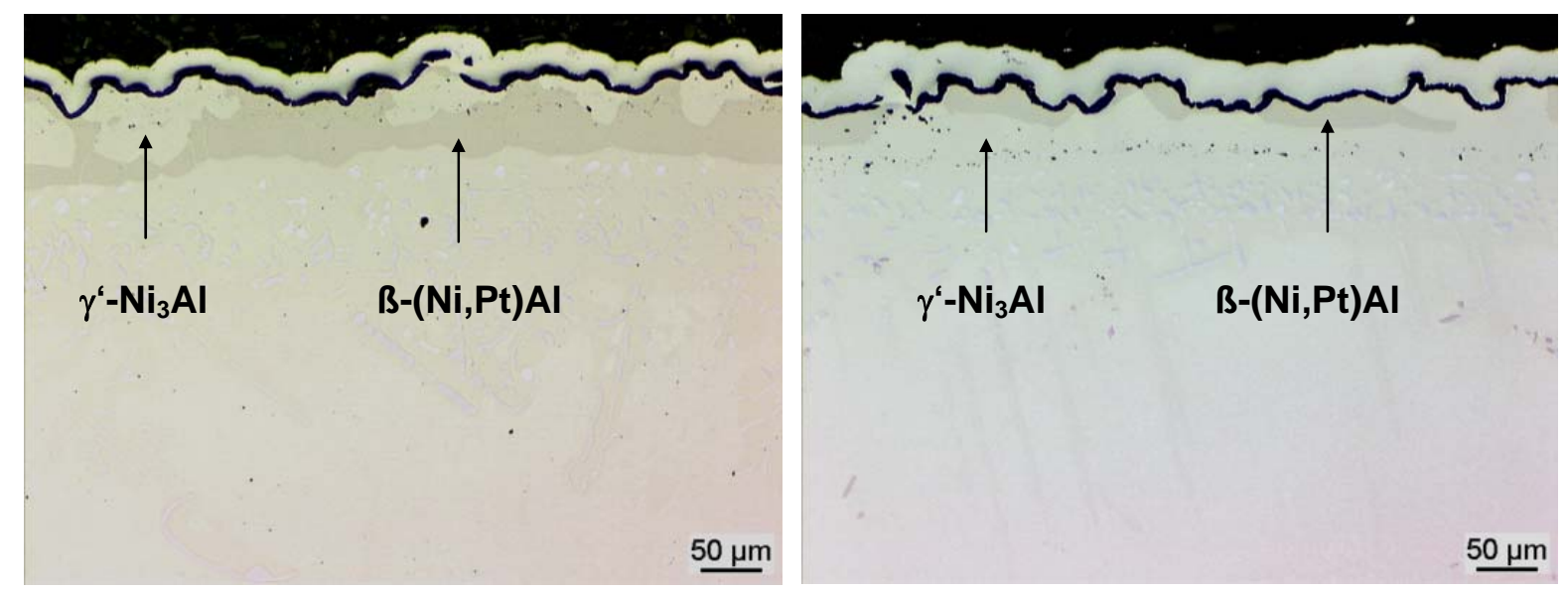

Fig. 13: Isothermal exposure after $750 \mathrm{~h}$ at $1200^{\circ} \mathrm{C}$, coating 1 (left) and coating 2 (right) 